\title{
Maria Beneyto: La creació literària de la dona múltiple i diversa al llarg del temps
}

\author{
[Maria Beneyto: The literary creation of multiple \\ and diverse women over time]
}

\author{
Josep BALlester-Roca \\ Universitat de València
}

ORCID ID: https://orcid.org/0000-0002-1995-3253

josep.ballester@uv.es

\begin{abstract}
Resum: Maria Beneyto es una de les autores fonamentals de la literatura valenciana de postguerra amb una llarga trajectòria tant en l'àmbit narratiu com poètic. Realitzem una petita introducció al voltant del context i les circumstàncies en les quals desenvolupa la seua activitat creadora i, a més, fem una anàlisi de la seua obra, que ens dibuixa, entre altres aspectes, una radiografia del signe femení contemplat des de la diversitat i el compromís. Per aquest motiu estudiem aquest tipus d'imatges relacionades amb els referents ficcionals i reals tot reivindicant una identitat marcada per la diferència.
\end{abstract}

Paraules Clau: Maria Beneyto, literatura feminista, literatura de postguerra

Aвstract: Maria Beneyto is one of the fundamental authors of post-war Valencian literature with a long career in both the narrative and poetic fields. We make a short introduction about the context and circumstances in which he develops his creative activity, in addition, we make an analysis of his work, which draws us, among other things, an x-ray of the female sign seen from the diversity and the commitment. For this reason, we study this type of image related to fictional and real references, claiming an identity marked by difference.

KeYwords: Maria Beneyto, feminist literatura, postwar literature 


\section{Postguerra i bilingüisme literari ${ }^{1}$}

El dilatat itinerari d'aquesta dona de lletres, tant en la vessant poètica com en la vessant narrativa, la converteix en una de les escriptores més interessants i fonamentals de la literatura de postguerra, tant en llengua catalana com en llengua castellana al País Valencià. La situació dels creadors en aquells anys de repressió era excepcional, almenys en la nostra llengua. S'hi trobaven en l'actitud d'un replegament defensiu, ja que la literatura no podia ser un fenomen social, sinó senzillament com a testimoni. Els primers textos en català que va llegir la nova generació eren anacrònics i molt llunyans dels vents estètics que bufaven a Europa. Així, els autors més joves van haver de començar a escriure en castellà i segons els cànons oficials. Recordem els primers poemes publicats per V. Andrés Estellés a la revista Fantasía, germana estètica de Garcilaso o els primers textos poètics de Joan Fuster, que fins i tot va arribar a presentar-se, l'any 1947, al Premi Adonáis. En contra dels pronòstics, però, a l'inici de la dècada dels cinquanta, el nombre d'escriptors va augmentar, com també el minso públic lector.

En aquest complex context que acabem de descriure, hem d'incorporar algunes claus per comprendre la singularitat i sobretot la rellevància de Maria Beneyto, ja que en primer lloc, hem de subratllar que ens trobem davant d'una escriptora, per tant, primer entrebanc i important, ja que la seua obra trenca els models franquistes assignats de forma tradicional a la identitat femenina; i segon tret diferencial, no per això menys decisiu, duplica la seua veu en una llengua vetada. A més, pensem que la seua família pertanyia al bàndol dels perdedors de la Guerra Civil. De fet, ja des de l'inici de la seua trajectòria apreciem un desafiament al silenci que va imposar el règim franquista sobre la identitat dels vençuts.

De fet, podem suggerir alguns aspectes sense els quals es fa impossible entendre i copsar aquells anys durant la postguerra, sense tenir present la con-

1 Per a aprofundir en aquest context de la postguerra valenciana podeu veure Ballester (2006) i (2019).

REVISTA VALENCIANA DE FILOLOGIA / IV (2020) p. 75-93

JOSEP BALLESTER-ROCA

Maria Beneyto: La creació literària de la dona múltiple i diversa al llarg del temps / 76 
juntura i la situació de la llengua com d'una manera molt perspicaç apunta Fuster (1969: 274): «No defenso ni justifico el bilingüisme; ni tan sols no intento mostrar-lo com explicable [...] Però és dolorós també, i nociu, per al propi escriptor que el pràctica».

D'altra banda, però, també hem de tenir en compte les circumstàncies biogràfiques de l'escriptora, que, en aquest cas, van ser superades gràcies a una presa de posició clara i decidida. Recordem que Beneyto, sense cap necessitat, va duplicar la seua veu creativa: «Castellana ha estat la meua formació. Castellà s'ha parlat sempre a casa, i a Madrid, on vaig viure deu anys d'infantesa, tu em diràs com es parlava. No obstant això, vaig escriure en català, amb un gran esforç, perquè ho considerava un deure i un deute amb la meua terra» (Ballester 1993: 3). D'aquesta manera, ara en una llengua o ara en una altra va fer camí en la seua obra com a escriptora.

Unes breus pinzellades entorn de la seua biografia, ens pot ajudar a esbossar la trajectòria d'aquesta autora. Maria Beneyto va nàixer el 14 de maig de 1925 i va morir el 15 de març de 2011 a la ciutat de València. La seua família es va traslladar a Madrid quan era molt petita (en concret, tenia tres anys), etapa vital definida per l'escriptora com molt dura. El motiu del trasllat familiar obeeix al desig patern d'intentar estrenar alguna de les seues peces teatrals a la capital de l'estat espanyol, però, no ho va aconseguir, tal com es reflecteix en la novel-la autobiogràfica de la nostra autora, Antigua patria (1969). En plena guerra, quan el govern republicà es trasllada a València, la família Beneyto torna a la ciutat d'origen. No obstant això, la situació no va diferir substancialment dels esdeveniments viscuts a Madrid, com tampoc després en la postguerra, ja que igual que per a la majoria de la població no addicta a el règim, van ser temps molt complicats. Set o vuit anys després, la situació familiar va canviar gràcies a l'arribada d'una herència. Aquest inesperat gir econòmic, va permetre a la jove Beneyto, que aleshores tenia uns vint anys, complir l'aspiració més íntima: dedicar-se completament a l'escriptura. Ara posseïa els mitjans i el temps per poder intentar-ho. Eren les condicions materials de la creació femenina apuntades per Virginia Woolf a A Room of One's Own.

REVISTA VALENCIANA DE FILOLOGIA / IV (2020) p. 75-93

JOSEP BALLESTER-ROCA

Maria Beneyto: La creació literària de la dona múltiple i diversa al llarg del temps / 77 


\section{Esbós de l'obra literària ${ }^{2}$}

Des de Canción olvidada (1947) fins a l'actualitat, Maria Beneyto va traure a la llum més de quaranta obres de creació, entre les quals destaquen Altra veu (1952) editat a Torre, que va rebre la menció honorífica del premi Joaquim

Folguera dels Jocs Florals de la llengua catalana a l'exili de 1953, celebrats a Caracas; Eva en el tiempo (1952) publicat a la col-lecció de la revista El sobre literario o Criatura múltiple (1954), amb el qual va guanyar el premi València de poesia. El 1956, Torre publica Ratlles a l'aire, quan ja l'escriptora, que havia lliurat l'original feia molt de temps, no s'ho esperava. Mentrestant, l'havia presentat al premi Ciutat de Barcelona, amb el qual l'obra va ser guardonada quan acabava de publicar a València. A Barcelona va tenir cert èxit, de manera que l'editorial Faro va traure una segona edició el 1958. Ja en la dècada dels seixanta té una incidència important en la narrativa i publica un nombre gens menyspreable d'obres, entre les quals destaquen El río viene crecido (1960), premi València de Literatura; el volum de contes La gent que viu al món (1966); La dona forta (1967), que guanya el Premi Senent de novel·la o Antigua patria (1969) que rep el premi Ciudad de Múrcia. Més tard publica a Caracas, El agua que rodea la isla (1974) i el 1976 guanya el premi

2 El valor i l'entitat literària de l'obra de Beneyto és ben rellevant com ha estat reconegut a través dels premis o guardons que se li han atorgat al llarg de la seua trajectòria, entre altres podem mencionar: el Premi Ciutat de València, l'Ausiàs March, Premi Internacional Calvina Terzaroli d'Itàlia, el Ciutat de Barcelona o el Premi de les Lletres Valencianes que atorga la Generalitat Valenciana. La crítica especialitzada l'ha reconeguda i també ha estat recollida en diverses antologies poètiques editades des dels inicis de la dècada dels cinquanta fins a l'actualitat: Joan Triadú, Antologia de la poesia catalana (1900-1950) (1951); Carmen Conde, Poesía femenina española viviente (1954), Joan Fuster, Antologia de la poesia valenciana (1900-1950) (1958); J. María Castellet, Veinte años de poesía española (1960); Segunda Antología de Adonáis (1962); J. L. Cano, Antología de la nueva poesía española (1963); Josep M. Castellet i Joaquim Molas, Poesia catalana del segle Xx (1963); Maria Romano Colangeli, Voci femmenili della lirica spagnola del 900 (1964); Leopoldo de Luis, Poesía social española contemporánea (1965); Lluís Alpera, Identity Magazine. Antologia de la poesia realista valenciana (1966); Manuel Montero, Poesía española contemporánea (1966); Josep M. Castellet i Joaquim Molas, Ocho siglos de poesía catalana (1969); Mujer soy. La voz femenina en la poesía social y testimonial de los años cincuenta (2006) d'Angelina Gatell; En voz alta. Las poetas de las generaciones de los 50 y los 70 de Sharon Keefe Ugualde (2007); l'antologia i exposició Dones=Poetes (2011) de Lluïsa Cotoner, Teresa Julio, Caterina Riba i Judith Sánchez. Tot això com una mostra.

REVISTA VALENCIANA DE FILOLOGIA / IV (2020) p. 75-93

JOSEP BALLESTER-ROCA

Maria Beneyto: La creació literària de la dona múltiple i diversa al llarg del temps / 78 
Ausiàs March amb Vidre ferit de sang. Després ve un llarg parèntesi de silenci en l'escena literària pública d'aproximadament vint anys en què no publica ni un sol llibre. Més tard va ressorgir com l'au Fènix i en la dècada dels noranta, a part de diverses antologies i reedicions de l'obra, va publicar entre d'altres Nocturnidad y alevosía (1993), Després de soterrada la tendresa (1993), Hojas para algun día de noviembre (1993), Para desconocer la primavera (1994), Elegies de pedra trencadissa (1997), El mar, desde la playa (1999), Balneario (2000), Bressoleig a l'insomni de la ira (2003), obra per la qual se li va concedir el Premi de la Crítica Catalana o Poesía Completa (1947-2007). En definitiva, una important eclosió literària, no sols en quantitat sinó també i sobretot, en qualitat.

Una de les constants més destacades en l'obra de Beneyto rau en la seua capacitat per formular l'angoixa i el sentiment de les limitacions humanes del nostre temps. La presència de l'ésser humà $i$, de forma més concreta, d'aquells més desvalguts adquireix una gran força en la seua creació. El dolor que suggereix es converteix en el ressò del sofriment de la humanitat. Com apunta Sanchis Guarner (1967: 5): «L'amor als febles la porta a rebel-lar-se amb coratge contra la injustícia, a compartir el dolor de les víctimes de l'opressió» i a convertir-se en la veu dels marginats (i entre ells, és clar, la de la dona):

Jo somniava arbres, soterrant l'alegria.

Dins de mi, la sang de l'horta en la ciutat glatia.

Em presentia dona tota silvestre encís, tota de llum i terra, branca del paradís. $(R A: 1067)^{3}$

o

3 Les abreviatures de les obres que van entre parèntesi després de les cites corresponen als següents llibres de Beneyto: (RA) Ratlles a l'aire, (CM) Criatura múltiple, (DST) Després de soterrada la tendresa, (ET) Eva en el tiempo, (EPT) Elegies de pedra trencadissa, (PC) Poemas de la ciudad, (VFS) Vidre ferit de sang, (EL) Eva en el laberinto, (AV) Altra veu, (CPN) Casi un poco de nada, (LDF) La dona forta, (LGVM) La gent que viu al món.

REVISTA VALENCIANA DE FILOLOGIA / IV (2020) p. 75-93

JOSEP BALLESTER-ROCA

Maria Beneyto: La creació literària de la dona múltiple i diversa al llarg del temps / 79 
¿Quién me ha ordenado ineludiblemente

hablar con voz ajena a mi silencio, presintiendo, crecida, o recordando, existiendo a la vez de tantos modos? Yo, múltiple, plural, amigos míos, no soy nada. Soy todo. Soy aquella que se quejaba a Dios de no ser río y ser mar, ser clamor y no palabra, ser calle de ciudad y no sendero, ser colmena y no ser única abeja. (CM: 161-162)

L'obra de Beneyto es transforma en el retrat de la dona al llarg de el temps, una mena de dietari «en què el que s'expressa no són els fets, sinó la forma d'una mirada concreta, la dicció d'una sensibilitat en contrast amb els esdeveniments que presencia i que ens fa presenciar» (Martí 1994: 9). A través de cada un dels seus llibres, l'autora ens regala una radiografia tant interior com exterior de les dones, del «signe femení» com ella ho designa, però des d'un punt de vista plural, divers i compromés. Per aquest motiu, apreciem en els seus llibres la presència constant de la realitat assignada de forma tradicional a la dona i de tot el ventall d'estereotips naturalitzats per la societat per a representar-la, com la mare, l'esposa i la mestressa de casa, però, l'autora no es limita a una descripció enumerativa de figuracions prefixades sinó que les sotmet a un conscient exercici de reescriptura que genera noves construccions de la feminitat o podríem dir des del feminisme.

REVISTA VALENCIANA DE FILOLOGIA / IV (2020) p. 75-93 JOSEP BALLESTER-ROCA

Maria Beneyto: La creació literària de la dona múltiple i diversa al llarg del temps / 80 


\section{Algunes imatges de la diversitat i la diferència ${ }^{4}$}

Al llarg de la història de la humanitat les dones han gaudit de poques o nul-les possibilitats de crear imatges pròpies de la feminitat, i en el temps, han hagut d'assumir la imposició dels models totalment viciats i construïts pels homes. Així, durant un llarg període, l'etern femení s'ha interpretat com una mena de visió de la bellesa angelical i la dolçor en els sentiments, ja que la dona ideal es defineix com una criatura passiva, dòcil i feble de caràcter. Quant això, Sandra Gilbert i Susan Gubar (1979: 25) amb la ironia que les caracteritza afirmen:

No tenir personalitat no és solament ser noble, sinó estar morta. Una vida sense història, com la vida de Makarie de Goethe, és una vida de mort, és la mort en vida. L'ideal de puresa contemplativa evoca, en darrer terme, tant al cel com al cementiri.

La imatge de docilitat $\mathrm{i}$ innocència concebuda per la psique masculina en l'obra de Beneyto s'esquerda fins a la seua eliminació, ja que la condició femenina s'afirma des de la renúncia a aquests trets tradicionalment assignats al llarg de la història:

Pisaré tierra firme, asfalto firme, piedra renunciaré al refugio donde está la inocencia la dulzura evasiva, queriéndome anestesiarme (PC: 220)

en aqueixos nous vents de la dona que em porta

—dona i no àngel— per la voravia. (RA: 1071)

Si tota imatge té el seu anvers, en el cas d'aquesta figuració femenina gestada pels dictàmens socials i pel poder patriarcal, el revers correspon a aquella

4 Vegeu Ballester (1995: 87-94), Ballester i Ibarra (2016) on hem tractat alguns aspectes de la presa de consciència del punt de vista de la feminitat per part de Maria Beneyto.

REVISTA VALENCIANA DE FILOLOGIA / IV (2020) p. 75-93

JOSEP BALLESTER-ROCA

Maria Beneyto: La creació literària de la dona múltiple i diversa al llarg del temps / 8 I 
part amagada darrere de les vestidures de bondat i bellesa, el monstre, com a símbol del pànic de l'home a la rebel-lió de la dona, a la por d'enfrontar-s'hi en termes d'igualtat.

Així ho explica Celia Amorós (citada per Victoria Seu 1990: 203):

No creo que haya razón metafísica alguna para que el hombre tema a la mujer: la teme porque la oprime, y sobre todo la ha oprimido duramente, y en la medida en que pretende — sutilmente- seguir oprimiéndola para mantener una identidad — la identidad masculina - construida sobre la base de esta opresión. No la oprime porque la teme, sino al revés.

Des d'aquesta perspectiva, la figuració del monstre correspon també a aquella dona que no renuncia al seu punt de vista i rebutja el paper submís i passiu que se li ha assignat durant segles. La literatura i la mitologia ens han obsequiat amb una rica galeria d'aquests personatges, a través de figures gairebé sempre terribles des de la tradició, com són la Medusa, l'Esfinx, Circe, Pandora, Medea, Dalila, Salomé, les bruixes, les sirenes o les amazones. Hélène Cixous i Catherine Clement (1986: 357) expliquen la construcció i l'ocupació utilitarista de personatges creats des de la tradició masclista com els tipus de la histèrica o la fetillera com a figures representatives, encara que extremes de l'experiència femenina.

Si bé en l'obra de Maria Beneyto podem trobar alguns d'aquests personatges, la seua representació no obeeix a la vessant radical de l'experiència femenina. Així per exemple, l'arquetip de la sirena es converteix en una veu que reivindica i mostra la seua solitud en la lluita constant de la vida, sense més opció que l'exili:

Ací estic. Escolteu-me. Ja sóc sola.

Vinc Una altra vegada plena d'ecos

a dir-vos la paraula ... Ja sóc sola

¿Ja no obrirà mai porta l'exili?

[...] Sóc criatura d'aigua en 1 'enyorança

i a penes tinc de mar a els ulls i a els somnis.

REVISTA VALENCIANA DE FILOLOGIA / IV (2020) p. 75-93

JOSEP BALLESTER-ROCA

Maria Beneyto: La creació literària de la dona múltiple i diversa al llarg del temps / 82 
Germanes mudes ja sota les ones,

¿sóc sola ací, sola a la mar per sempre...? (RA: 1079).

Com també la iconografia generada per les bruixes com dones poc femenines pel seu distanciament del model de dona creat pel patriarcat, en els textos de la nostra escriptora es transformaran en el suport que necessita la veu poètica per seguir endavant, en el sosteniment per mostrar el camí a seguir:

Mai no podré arribar al pont,

el meu destí és restar

a mig camí...

Elles assolaran totes les portes, no cal que tanques. És inútil. (VFS: 1091-1092)

Dins d'aquest bagatge de personatges i de símbols que representen la condició femenina, destaca l'epònim de la boja, citat per Gilbert i Gubar (1979: 31) que trobem a la majoria de les escriptores. De forma concreta, se centren en Bertha Mason de Jane Eyre de la qual apunten:

Generalment és la doble de l'autora, en cert sentit, una imatge de la seua ansietat i la ràbia. De fet, gran part de la poesia i de la novel·la escrita per dones evoca aquesta criatura perquè les autores puguen confrontar el seu sentiment de fragmentació propi i únic de dones, la seua pròpia consciència de les discrepàncies que hi ha entre el que són i el que haurien de ser.

Aquesta interpretació és aplicable, així mateix, a un gran nombre dels personatges que apareixen en l'obra de Beneyto, ja que la majoria són estranys i foscos, de vegades contradictoris, amb múltiples identificacions com a dona i en constant transformació: «Blaus ulls de l'aire / miren la dona que sóc, estranya / i boja, / disminuir, a la infantesa caure / per a millor anar-se'n cap enrere / i com acord inèdit, / ser feliçment somniada» (1158) del poema «Matí a la mar» d'EPT o en el text del mateix llibre «Ací, a la vida, tot és massa tèrbol», en el que les dones s'han animalitzat fins transformar-se en monstres: «Les dones ja

REVISTA VALENCIANA DE FILOLOGIA / IV (2020) p. 75-93

JOSEP BALLESTER-ROCA

Maria Beneyto: La creació literària de la dona múltiple i diversa al llarg del temps / 83 
no són dones, / són feres amb el cadell al coll, / i cauen / les ciutats al buit: / enderrocs i cadàvers / fan muntó... ¿Què et diria?» (1170).

A través de Beneyto entenem amb Toril Moi (1985) com la figura de la boja es converteix en una estratègia literària emblemàtica i sofisticada, a través de la qual realitzar una lectura revolucionària d'aquests personatges. Des d'aquesta òptica, tots constitueixen, en definitiva, una imatge de l'escriptora, una doble en la qual l'autora vol escapar de les fórmules creades pels homes. Ací ens suggereix un exemple:
Somies un record de dones folles, astorades, que van alhora cridant-te, però no el nom proper, el que tens ara, sinó l'altre, el de la llum que un dia et varen amagar, el nom d'origen que desconeixes tu, el que retenen amb la llum que no tens i saps que és teua, i que la té potser empresonada algú que vol tornar-te-la... la resta l'has endevinat. Les dones parlen i no les pots entendre. (BII: 28)

En l'esquema del pensament binari patriarcal (activitat/passivitat, cultura/ naturalesa, dia/nit, lógos/páthos, etc.) Cixous i Clement (1975) oposen la diferència múltiple $i$ heterogènia de la feminitat. Reivindiquen que els textos escrits per dones tracten la diferència, lluiten contra la lògica falocèntrica dominant, trenquen les limitacions d'oposició binària i gaudeixin amb els plaers d'un tipus d'escriptura més oberta. L'obra literària de Beneyto resulta particularment interessant, fins i tot se'n podria dir pionera, pel que fa a l'acompliment d'aquesta proposta, ja que com de manera precisa comenta Ugalde (2013: 56$57)$, en aquesta es determinen dos camins per a la transformació del gènere:

La primera es la desarticulación del modelo jerárquico patriarcal. Consiste en rescatar del espacio semiótico maternal una esencia femenina 
antigua desprestigiada. Lo antes denegrido o inferior ahora se valora: lo irracional, el tiempo dilatado y cíclico, la unión con la naturaleza, la inmanencia, el Otro. La segunda senda es concebir el género como una construcción provisional de repetidos discursos, gestos, y movimientos estilizados. Este concepto significa que con cada performance el sujeto «mujer» puede participar en la modificación del género. Ella es construida y constructora. En ambas sendas María Beneyto sobresale como poeta feminista precursora, anticipando por casi cuatro décadas las teorías del género más señaladas de fines del siglo xx. Aplaudamos una performance que contribuye al desencasillamiento de las mujeres.

D’una manera o d'una altra, però sempre amb una freqüència constant, Maria Beneyto ha manifestat la diversitat i la multiplicitat de la condició femenina en la seua obra, des de molts dels seus títols i en la majoria dels seus textos. Des d'aquesta multiplicitat ens situa davant l'univers humà com un símbol personal i com una imatge col-lectiva de les dones. Construïda i reescrita en cadascun dels seus llibres.

\section{Vindicació d'alguns mites i referents}

Un cas ben interessant és la utilització d'alguns mites, referències bíbliques, personatges ficticis o reals per part de la nostra escriptora al llarg de tota la seua obra. En la mitologia hebrea, el primer ésser humà dona i, per tant, mare de la humanitat va ser Eva. El Gènesi planteja dos relats ben diferents de la creació de la dona, d'una banda, Adam i Eva són creats simultàniament per Déu, de l'altra, a Adam mentre dorm li extrau una costella de la qual naix Eva. El cristianisme ha remarcat l'accent en la segona versió. Així, la dona és feta a imatge de l'home i l'home, en canvi, a imatge de Déu. A més, cal afegir que la primera dona va arrossegar Adam a la mort i al pecat.

Tanmateix, Ernest Borneman (1975) apunta que la consciència del jo (maduresa psíquica) és adquirida abans per la dona si seguim el mite de la

REVISTA VALENCIANA DE FILOLOGIA / IV (2020) p. 75-93

JOSEP BALLESTER-ROCA

Maria Beneyto: La creació literària de la dona múltiple i diversa al llarg del temps / 85 
caiguda i pecat original, en el qual hi ha dos moments: 1) adquisició del coneixement per part d'Eva i 2) com Adam la rep de la dona. A partir d'aquesta interpretació Elisabeth Russell (1985) comenta que la serp va dir a Eva que si menjava el fruit seria igual que Déu i coneixeria el bé i el mal, perquè se li obririen els ulls. Eva va menjar i després va voler fugir del paradís per a descobrir una terra nova i reidentificar la seua pròpia personalitat. Però, és clar, la còlera de Déu va ser implacable i el càstig explícit: «Et multiplicaré els dolors i els embarassos; tindràs els fills amb dolor. El teu desig t'impulsarà cap al teu home, i ell et voldrà sotmetre» (Gènesi, 1:16). D'aquesta manera, qui repta l'autoritat (patriarcal) ha de tenir en compte el preu terrible que haurà de pagar. Per la seua banda, la nostra escriptora ens presenta una Eva reivindicativa i lluitadora pels seus drets, que trenca i escapa del mur del paradís (la llar).

Yo era la mujer que se alzó de la tierra para mirar las luces siderales. Dejé el hogar con apagados troncos cansada de ser sólo estela de humo que prolongase así mi ser ardido. Esa mujer del hueco tibio que siempre fui y sería, se despertó del sueño profundo de la especie para buscar, a plena luz, caminos. (ET: 153)

$\mathrm{O}$

Bíblicas maldiciones inflamaron mi oído y me dijeron Eva una y mil veces, manantial del dolor, impúdica pureza, hembra evadida del rincón oscuro, del lugar de vigía en la ventana, desertora de la orilla del fuego y el hogar apagado. (EL: 543) 
No obstant això, les vindicacions d'aquesta Eva tan propera als nostres dies no difereixen de forma substancial de les de tots els éssers humans, ja que en realitat, es construeix com una veu testimonial que clama per trencar les cadenes i denunciar les injustícies dels més febles:

Debo dar testimonio del mal, lavar la herida enconada y terrible, esa sucia gangrena de la injusticia humana. Pongo el grito en el cielo y el amor cerca siempre del dolor de los otros. (ET: 133)

El mateix títol de la seua novel-la, La dona forta (1967), títol manllevat del text del llibre dels Proverbis ( $\operatorname{Pr}, 31: 10-31)$ on llegim a l'inici: «Una dona forta, qui la trobarà? És més preciosa que les perles. El seu marit confia en ella: no enyorarà cap més tresor». Fa un retrat d'una dona ideal, naturalment des del punt de vista masculí, com en la majoria dels textos bíblics. Aquesta dona forta al-ludeix, però a la dona perfecta, a la dona de vàlua $\mathrm{i}$ com cal segons aquests paràmetres. És ben interessant observar la coincidència de l'ús del referent bíblic en Beatriu Civera i Maria Beneyto, a més de la interpretació semblant que en fan les dues escriptores, per a les quals és una mostra del discurs patriarcal que ha fomentat el sotmetiment de la dona i que calia desemmascarar i deixar enrere, vegeu a propòsit d'això Lacueva i Ballester (2019). A més, en l'obra de Beneyto s'hi juga en l'ambivalència dels possibles significats, en el text de la novel-la sovinteja el qualificatiu fort/a o sinònims que al-ludeixen alguns dels seus personatges: «I sabia que en allò confiava Àgata. La tirànica, la forta Agata...» o «Tu, la forta, l'integra, l'olímpica, no m'has llegat res de tu mateixa, potser perquè jo vaig venir sense que tu em desitjasses...».

El resultat és una anada i tornada de personatges que entren i ixen en escena en cada capítol. Totes les vides dels actants transcorren paral-leles o entrecreuades entre si al voltant d'un club feminista. Les relacions i esdeveniments vivencials de cadascun d'ells —almenys d'aquells que hi apareixen amb més freqüència - serien com una història individual, podrien haver estat narrades

REVISTA VALENCIANA DE FILOLOGIA / IV (2020) p. 75-93

JOSEP BALLESTER-ROCA

Maria Beneyto: La creació literària de la dona múltiple $i$ diversa al llarg del temps / 87 
independentment. Aquest tret característic, així com també el gran nombre de personatges que hi pul-lulen, ens recorda novel-les com Mister Evasió, de Blai Bonet; La colmena, de Camilo José Cela; Ulisses, de James Joyce, o Contrapunt, d'Aldous Huxley. En La dona forta el protagonista és un personatge col·lectiu, com en les novel-les que hem esmentat. El grup actancial de les dones és el que genera la pròpia dinàmica del relat. I el grup dels homes, en definitiva, és un complement dels personatges actants (que en tots els casos són del sexe femení). Els personatges protagonistes són cinc dones de perspectives i relacions molt diferents, però que són aplegades al club. Cadascuna, seguint el nivell anecdòtic, és una individualització, però, si hi aprofundim fins al nivell simbòlic, dibuixa la dona enfrontada a les circumstàncies quotidianes i socials de la postguerra al País Valencià.

Ací tenen l'inici de la novel·la, tot un horitzó d'expectatives d'allò que hom hi pot trobar, possiblement en un dels relats escrits per creadors valencians més interessant d'aquestes dècades:

- [...] I mitjançant aquest acte que inaugura la temporada tardor-hivern 1953, el nostre Fèmina Club es proposa d'iniciar un seguit de...

La presidenta es detura per a beure's d'una tirada el got d'aigua que té davant. És alta i robusta, quasi en excés. Per això, es belluga una mica incòmodament dins del seu estret vestit negre [...] Està sòlidament plantada en terra sobre els seus grans peus. I segueix:

- Per sort, la dona, que tant injustament postergada ha estat durant segles... (LDF: 49).

Al costat d'Eva desfilen pels llibres de Maria Beneyto tant personatges anònims com dones amb nom propi que cobren vida a través de la creació i es converteixen en heroïnes que han desafiat les regles i els costums repressors de la societat patriarcal al llarg de la història de la humanitat. Així, per exemple, escriptores com George Sand, personatges com Òfelia, Bernarda Alba o Madame Bovary o l'admiració pels personatges que encarna, així com per la mateixa actriu Greta Garbo reflectida en dos excel·lents poemes, «Greta I de Suecia»

REVISTA VALENCIANA DE FILOLOGIA / IV (2020) p. 75-93 JOSEP BALLESTER-ROCA

Maria Beneyto: La creació literària de la dona múltiple i diversa al llarg del temps / 88 
i «Greta se ha ido", en què la interpretació de Garbo s'erigeix en un símbol reivindicatiu de totes les dones: ${ }^{5}$

Era el amor, pero otro amor, traía con carne estremecida y beso fiero la pasión, no encubierta, de la hembra que no se deja poseer, posee... Ignoro si era actriz, pero tenía de todas las mujeres que se fueron, y anticipó el futuro como suyo.

o

Su plenitud se queda, permanece en nosotros, amiga, compañera de dolor: con la adúltera suicida, con la mujer más humillada y sola, con la inconforme, con la represada, con las que lloran sueños que mueren nonatos tantas veces. (CPN: 466 i 469)

L'espai maternal constitueix, sens dubte, un dels elements temàtics més tractats i complexos de l'obra de Beneyto, en aquest treball sols ens cenyirem a un parell de mostres pel seu aspecte significatiu amb l'objectiu de verificar la diversitat de matisos i la profunditat d'aquest factor en tota la seua producció. Al-ludim a alguns dels relats que apareixen en La gent que viu al món (1966), per exemple, «Finestra al buit» on tracta les conseqüències socials i personals d'un amor truncat per la guerra. En aquest cas i tot seguint la trajectòria creadora de Beneyto, les seqüeles d'aquella relació recauen en un personatge femení, Lluïsa, que viu atrapada en el seu passat. D’una banda, l'aspecte més íntim que determina el buit existencial que pateix i, de l'altra, la pressió social

5 Per a una anàlisi del poema «Greta I de Suecia» consulteu el treball de S. K. Ugalde (2006).

REVISTA VALENCIANA DE FILOLOGIA / IV (2020) p. 75-93

JOSEP BALLESTER-ROCA

Maria Beneyto: La creació literària de la dona múltiple i diversa al llarg del temps / 89 
i l'òptica que tenen de Lluïsa els altres. En aquesta ocasió hi ha una maternitat amagada per la pressió social de la moral del moment. Assumida, però, interiorment com una herència del gènere i de tot ésser vivent:

La seua mare, que de cap manera podria ser ja un cadàver sota la terra, duia, de llunyanies remotes, la veu i l'herència de totes les dones que l'havien precedit, per a fer-la a ella dipositària d'un caliu i una noció de vides inèdites. Va sentir a l'instant la correguda de la saba per dins els arbres; va comprendre el gest del peix sota l'aigua dels rius pregons i la distensió al-lucinada de les plomes sobre l'aire. Es va reconéixer en l'insecte i en la forma més fera de la jungla. Es va trobar tota completa i en pau amb la creació sencera. (LGVM: 47-48).

O el cas d'Àgata, una de les protagonistes de La dona forta, representa l'acceptació de la maternitat sense necessitat de la intervenció posterior de l'home. Sense cap mena de dubte, una postura feminista i clarament progressista en el sentit ideològic (Lacueva 2013; Pérez Montaner 1996).

\section{A manera de conclusions}

L’obra de Maria Beneyto exhibeix una nítida denúncia al voltant de la condició social i històrica de la dona i les limitacions de l'estructura lògica del patriarcat. El seu quefer literari es transforma en l'escriptura d'un diàleg múltiple però també en la reivindicació d'una identitat marcada per la diferència a partir de la creació d'una veu off-center discourse.

En aquest sentit, podem percebre un desafiament constant en la seua creació, ja que tota la seua escriptura es caracteritza per no seguir les pautes i els dictàmens, primer com a pertanyent al bàndol maleït dels perdedors de la Guerra Civil Espanyola; després com a dona; i a més mitjançant l'ús conscient d'una de les llengües vetades per la dictadura franquista, i finalment, en no

REVISTA VALENCIANA DE FILOLOGIA / IV (2020) p. 75-93 JOSEP BALLESTER-ROCA

Maria Beneyto: La creació literària de la dona múltiple i diversa al llarg del temps / 90 
seguir els cànons estètics ni ideològics defensats per la crítica imperant en cada moment.

No obstant això, tot i la complexitat del seu univers i la singularitat de la seua veu, o precisament pel cúmul de factors subversius que hem esmentat anteriorment, l'escriptora no gaudeix del protagonisme literari d'altres contemporanis. Així, Max Aub en la seua punxant La gallina ciega (1971), on explica el seu retorn l'any 1969 a una Espanya que no havia trepitjat en trenta anys després d'un llarg exili, denuncia la situació social d'alguns escriptors i en particular al-ludeix de manera directa i perspicaç a l'oblit en què havia caigut, no sols l'obra, sinó també la persona de Maria Beneyto:

Hay en la poesía de Maria Beneyto un dolor sincero, una angustia, una tristeza de la época que la ponen a veces a la altura de José Hierro, de Blas de Otero. En Valencia no lo saben o no quieren saberlo. La tienen, como a Juan [Gil-Albert], olvidada. Ni siquiera aparte: confundida con las obras del «ensanche». Prefieren sus García Sanchiz y otras Marcelinas. No es bastante especiada para sus actuales paladares. Y ella se ha resignado de buena o mala gana (no lo sé). Le falta, como a todos, empenta. Mas la culpa no es suya. ¿Desde cuándo no han tenido en Valencia un poeta de este aliento? No les importa. No es razón para callarlo, aunque ella no diga nada (Aub 1971: 386).

Com hem analitzat, en els llibres de la nostra escriptora el seu univers creatiu sempre complex passa pel filtre femení, plural i divers. La mateixa concepció de l'escriptora com a ésser humà ve determinada per aquest signe ineludible i reivindicatiu. Des d'aquesta perspectiva podem afirmar que l'obra literària de Beneyto transfereix el perfil de la dona al llarg de el temps, ja que en la seua escriptura intenta donar veu als que no la tenen; escriptura, d'una banda, que presenta el futur i recorda el passat; i, de l'altra, escriptura solidària en què la creadora dona cabuda a una multiplicitat d'identitats.

Una obra prolífica i variada tant en prosa com en vers, tant en castellà com en català ens dibuixa una mena de diari de navegació de la seua trajectòria

REVISTA VALENCIANA DE FILOLOGIA / IV (2020) p. 75-93

JOSEP BALLESTER-ROCA

Maria Beneyto: La creació literària de la dona múltiple i diversa al llarg del temps / 9I 
íntima i col-lectiva. Cadascun dels seus llibres ens ofereix un minuciós traçat de la radiografia interior i exterior de les dones, dels desvalguts de la societat, del signe femení des d'un punt de vista sempre polièdric, múltiple i compromés.

\section{Bibliografia}

Obres i edicions utilitzades de Maria Beneyto

BAllester-Roca, J. (1990 [1a ed. 1967]) «Introducció i edició», dins Maria Beneyto, La dona forta, Valencia, Institució Valenciana d’Estudis i Investigació, pp. 7-40.

— (1997 [1a ed. 1966]) «Introducció i edició», dins Maria Beneyto, La gent que viu al món, Alzira, Bromera, pp. 5-42.

Beneyto, M. (2002) Bressoleig a l'insomni de la ira, Alzira, Bromera.

Rodríguez Magda, R. M. (2008) «Introducció i edició», dins Maria Beneyto, Poesía completa (1947-2007),València, Ajuntament de València, pp. 9-99.

REFERÈNCIES BIBLIOGRÀFIQUES

Aub, M. (1971) La gallina ciega, Mèxic, Joaquín Mortiz.

Borneman, E. (1979) Le patriarcat, París, PVF.

Ballester-RocA, J. (1993) «Entrevista a Maria Beneyto: A la meua obra hi ha un sentiment d'absència i una certa propensió al drama. El corb de Poe té part de la culpa", Avui. Suplement de Cultura, 26-XI-1993, pp. 3-4.

- (1995) La poesia catalana de postguerra al País Valencià, València, Tres i Quatre.

- (2006 edició ampliada [1a ed. 1992]) Temps de quarantena. Cultura i societat durant la postguerra al País Valencià, València, Publicacions de la Universitat de València.

- (2019) «Escriptores i cànon en temps de quarantena», dins Maria Lacueva Lorenz, Les dones fortes. La narrativa valenciana sota el franquisme, València, Institució Alfons el Magnànim, pp. X-Xx.

Ballester-Roca, J.; Ibarra-Rius, N. (2016) «La escritura de la identidad femenina y feminista: La voz pionera de Maria Beneyto», Tonos Digital. Revista de Estudios Filológicos, 31 (juny 2016), s.n.

Cixous, H.; Clement, C. (1975) La Jeune Née, París, UGE.

- (1986) The Newly Born Woman, Minneapolis, University of Minnesota Press.

Fuster, J. (1969) Diari (1952-1960), OC, vol. I, Barcelona, Ed. 62.

Gilbert, S.; Gubar, S. (1979) The Madwoman in the Attic: The Woman Writer and the Nineteenth-Century Literary Imagination, New Haren, Yale University Press.

Lacueva, M. (2013). Elles prenen la paraula. Recuperació crítica i transmissió a les aules de les escriptores valencianes de postguerra: una perspectiva des de l'educació literària, tesi

REVISTA VALENCIANA DE FILOLOGIA / IV (2020) p. 75-93

JOSEP BALLESTER-ROCA

Maria Beneyto: La creació literària de la dona múltiple i diversa al llarg del temps / 92 
doctoral (director: Josep Ballester), Departament de Didàctica de la Llengua i la Literatura, Universitat de València. Disponible en: http://roderic.uv.es/handle/10550/32131 (Consulta: 10/05/2020).

Lacueva, M.; Ballester, J. (2019). «Masclisme(s) i vida quotidiana durant el franquisme: la reelaboració literària de Beatriu Civera i de Maria Beneyto", Zeitschrift für katalanistik, 32, pp. 319-341.

MarTí, A. (1994). «Les latituds poètiques del dietari». L'Aljamia. Revista de creació literària, 7, pp. 9-10.

Moi, T. (1988. Teoría literaria feminista, Madrid, Cátedra.

Pérez Montaner, J. (1996) «Algunes puntualitzacions sobre la narrativa de Maria Beneyto", L’Aiguadolç, 22, dossier Maria Beneyto, pp. 37-48.

Russell, E. (1985) «A la recerca del paradís: la utopia vista per una dona», Encontre 2, pp. 69-74.

Sanchis Guarner, M. (1967) «Pròleg», dins Maria Beneyto, La dona forta, València, Senent, s.n.

Ugalde, S. K. (2006) «Remakes: Midcentury Spanish women poets and the gendering of film imagery. Leading ladies", dins Yvone Fuentes i Margaret R. Parker (eds.) Mujeres en la literatura hispana y en las artes, Baton Rouge, Lousiana State University Press, pp. 165-171.

— (2013). «María Beneyto: ¡No me encasilles!», Cuadernos de Aldeeu 26, pp. 43-62.

SEu, V. (1990) Diccionario ideológico feminista, Barcelona, Icaria.

REVISTA VALENCIANA DE FILOLOGIA / IV (2020) p. 75-93

JOSEP BALLESTER-ROCA

Maria Beneyto: La creació literària de la dona múltiple i diversa al llarg del temps / 93 


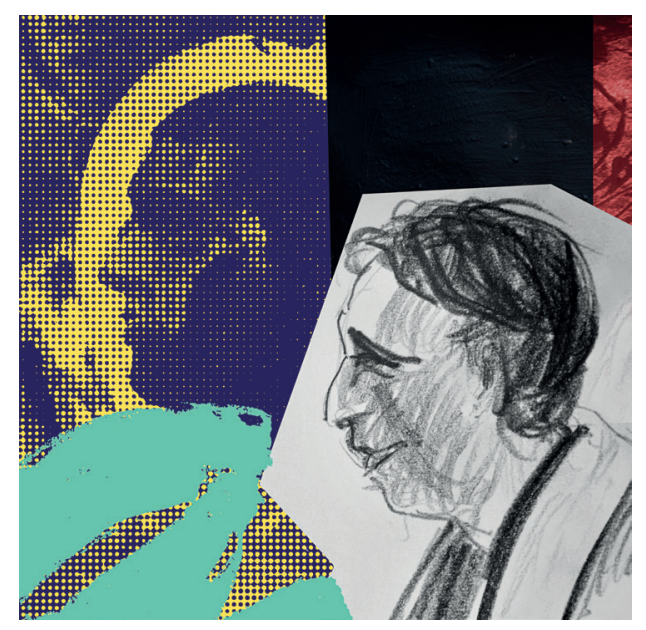

DAVID MARquÉs. Altered hyperbolae IV, 2020. Collage 